\title{
Increased sensitivity of the macroinvertebrate Paramorea walkeri to heavy-metal contamination in the presence of solar UV radiation in Antarctic shoreline waters
}

\author{
Sabine Duquesne ${ }^{1, *}$, Matthias Liess ${ }^{1,2}$ \\ ${ }^{1}$ Department of Chemical Ecotoxicology, UFZ Centre for Environmental Research, Permoserstrasse 15, 04318 Leipzig, Germany \\ ${ }^{2}$ Department of Limnology and Environmental Protection, PO Box 27, 00014 University of Helsinki, Finland
}

\begin{abstract}
A previous laboratory investigation showed that the Antarctic gammarid amphipod Paramorea walkeri is more sensitive to heavy metals when exposed to UV-B radiation. The question addressed in this study is whether this effect is also observed when the species is exposed to combined solar UV radiation and heavy-metal contamination under field conditions. In situ bioassays using $P$. walkeri showed that exposure to field contamination resulted in a significant decrease of survival. The effects observed were stronger than expected according to the characteristics of the contamination. The hypothesis that solar UV radiation can increase the sensitivity of organisms to metal contaminants was thus tested in an outdoor test system. This revealed that the mortality recorded under exposure to both parameters was increased compared to mortalities resulting from exposure to each single parameter. This increased sensitivity of amphipods to heavy metals in the presence of UV-radiation is discussed as an explanation for the absence of this species in contaminated shallow waters. The effects observed at the individual level would thus be reflected at a population level. This work highlights the necessity to consider environmental parameters such as UV radiation in Antarctica to improve the predictive power in ecological risk assessment.
\end{abstract}

KEY WORDS: UV-B · Heavy-metal contamination · Environmental parameters · Higher-tier risk assessment $\cdot$ Amphipod

Resale or republication not permitted without written consent of the publisher

\section{INTRODUCTION}

Interactions between contaminants and other types of environmental parameters are important to study as they can modify the biological response and induce additive or synergistic effects. For example, the sensitivity of aquatic organisms to contaminants such as heavy metals can be increased in the presence of ultraviolet (UV) radiation. This was shown in laboratory studies using a variety of organisms such as algae, rotifers and invertebrates (Rai \& Rai 1997, Preston et al. 1999, Liess et al. 2001).

In Antarctica, contaminants and UV radiation are 2 types of parameters that are of concern. Remote as it is, various types of contamination threaten the Antarctic ecosystem. The global distribution of toxicants and human activities around the South Polar Region are sources of chemical contamination. The potential is inherent in transportation activities, energy needs, waste disposal, etc. (Cripps 1990, Lenihan 1993, De Moreno et al. 1997). On the other hand, solar UV radiation has increased during recent years due to ozone depletion. UV-B has deleterious effects on living organisms by disrupting photosynthetic processes and damaging DNA (Bothwell et al. 1994). In addition, polar organisms suffer from exposure to high seasonal variations of UV intensities (Worrest \& Hader 1989). 
The question addressed in this study of Antarctic shoreline waters is whether the solar UV radiation changes the sensitivity of organisms to contaminants released in the field. The possibility is suggested by a study showing that exposure to UV-B in the laboratory increases sensitivity of amphipods to copper (Liess et al. 2001). The current investigation is based on a case study which involves (1) the characterization of contamination with heavy metals due to runoff from an old waste disposal site and of their ecological impacts, and (2) the response of organisms exposed to the combined parameters - solar UV radiation and heavy metals released in the field-using in situ bioassay, an outdoor test system and a field survey.

The study was performed using the gammarid amphipod Paramorea walkeri, as it is a representative species of the shoreline waters in this region and therefore suitable for the study of biological impacts of land-derived contaminants. It is frequently found in large numbers around rocks and among the red algae Iridea cordata and Phyllophera Antarctica, mainly in locations that are not severely exposed to wave action. Furthermore, it was identified previously as a potential
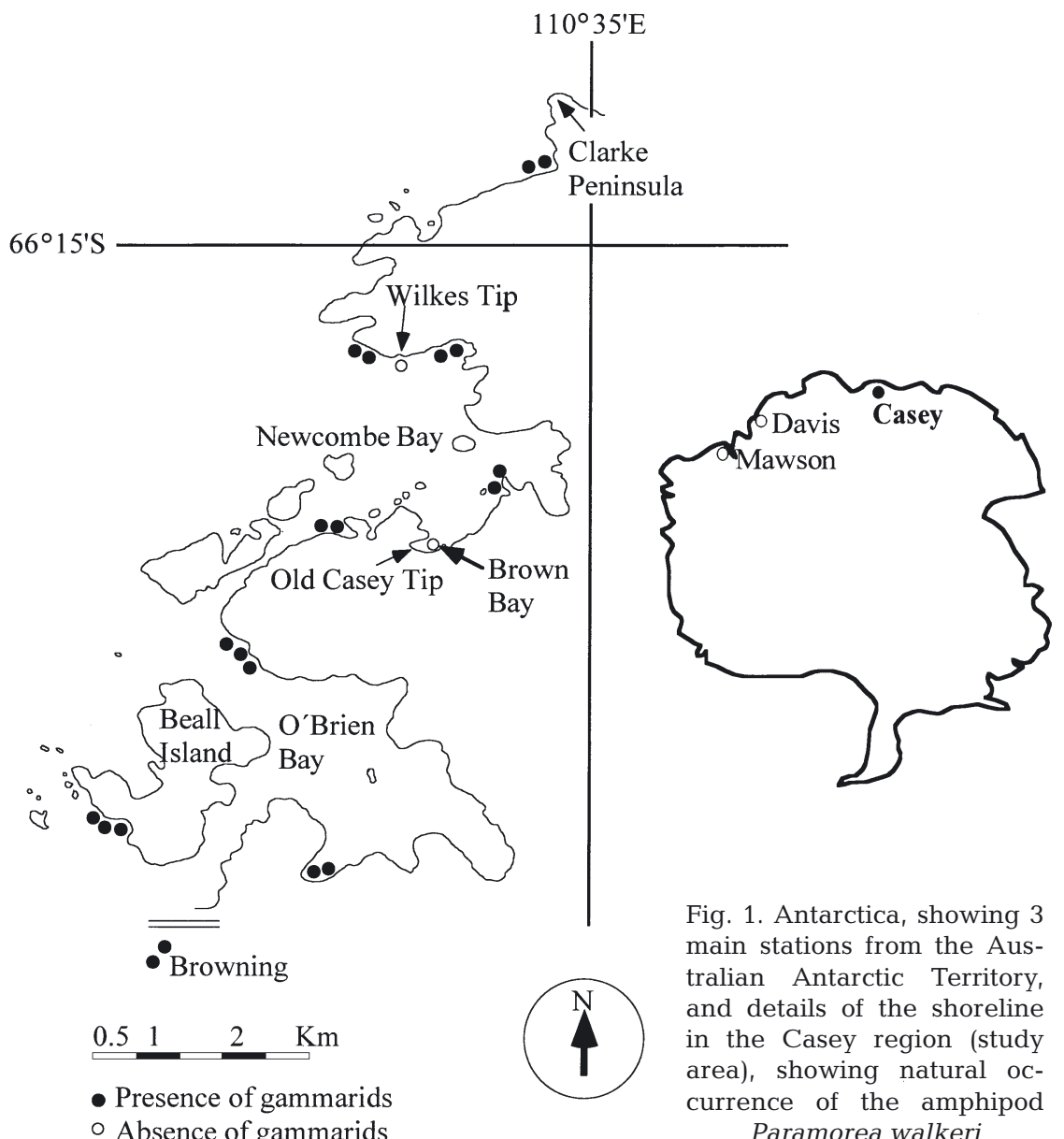

Fig. 1. Antarctica, showing 3 main stations from the Australian Antarctic Territory, and details of the shoreline in the Casey region (study area), showing natural occurrence of the amphipod Paramorea walkeri

\section{MATERIALS AND METHODS}

Study area. The investigation was carried out in February 1997 (in situ bioassay and field survey) and in December 1997 (outdoor test system and field survey) in the region of Casey station $\left(110^{\circ} 30^{\prime} \mathrm{E}\right.$, $66^{\circ} 17^{\prime} \mathrm{S}$; Australian Antarctic Territory), an area of rocky peninsulas and islands. It was conducted in the nearshore environment impacted by contaminants present in runoff from an old waste disposal site.

The shoreline region is relevant for investigating impacts of land-derived contaminants, given that the shoreline population (1) is the first to be influenced by runoff containing such contaminants, (2) has a simple community structure in the investigated case and (3) is dominated by a species that is widely distributed and represents the simple community well (the amphipod Paramorea walkeri). Furthermore, the shoreline is easy to access and sample, and is a relatively uniform environment.

The waste disposal site is located in a small valley close to the sea. Station wastes including domestic and construction materials from disused Casey station, which was operated between 1965 and 1986, were periodically dumped and routinely burned in this tip. During the summer thaw, melt-water flows through the tip and down towards the bay. Previous studies showed a concern about heavy-metal contamination (mainly $\mathrm{Cu}, \mathrm{Pb}$ and $\mathrm{Zn}$ ) in soil and leachates (Deprez et al. 1999, Snape et al. 2001). In this work we investigated the influence of this contami- 
nation on the adjacent bay. The following locations were selected: Brown Bay (adjacent to the tip site of interest), Newcombe Bay (adjacent to Brown Bay), and O'Brien Bay (reference site located about $4 \mathrm{~km}$ away from Brown Bay) (Fig. 1).

Characterization of the contamination. Dispersion of a tracer: To simulate the dispersion of contaminants from the tip outlet into the adjacent bay (Brown Bay), rhodamine was used as a tracer (Dyasyn-acid Rhodamine B01, Hoechst). A quantity of $200 \mathrm{~g}$ was released at the outlet. Approximately 100 seawater samples were then collected in Brown Bay and Newcombe Bay, at various depths (from 0 to $40 \mathrm{~m}$ ), over a period of $4 \mathrm{~d}$ using a suitable water sampler (Mercos, Hydrobios). The concentration of rhodamine was determined by fluorimetry (Turner Design; 350 and $420 \mathrm{~nm}$ ). This simulation helped us to select a suitable sampling strategy for the monitoring of contaminants released from the tip site and to find appropriate sites for in situ experiments.

Monitoring for heavy metals in various compartments: Sediment and water samples were collected at various locations to determine the degree of heavymetal contamination in the coastal environment.

Surface sediment samples were collected with a Van Veen grab from different sites within 3 areas: Brown Bay, Newcombe Bay and O'Brien Bay. They were stored in plastic bags and frozen until further handling using plastic gloves, spatula, cups etc. to avoid contamination of the samples. For each area, 3 composite samples made from the same 4 single samples collected within this area were analysed for heavy-metal concentrations in the total sediment. Because of the limited number of initial sediment samples, and the absence of appropriate standard reference material, the information obtained is only considered as an indication of the relative degree of heavy-metal contamination of the different areas.

Seawater samples were collected in 201 acid-rinsed low-density polyethylene containers (LDPE, Nalgene). The samples were immediately filtered through $0.45 \mu \mathrm{m}$ filters, $50 \mathrm{~mm}$ in diameter, previously rinsed in diluted nitric acid solution. Quartz glass-fibre filters (Schleicher \& Schuell) were selected in preference to glass-fibre filters for their lower heavy-metal residuals. The filters were kept for analyses in suspended particulates. Samples of $250 \mathrm{ml}$ of filtered seawater were acidified $(0.2 \%)$ and stored in LDPE bottles, which were carefully acid-rinsed before usage. Distilled water samples were handled similarly to seawater samples for blank analyses of water and filters. All samples were kept at $-20^{\circ} \mathrm{C}$ until analysis of heavy metals.

Assessment of the effects of field exposure on survival of individuals. In situ experiments: The gammarid amphipod Paramorea walkeri was used to investigate the biological effects due to environmental conditions. Individuals were collected with hand nets at a reference site (Beall island) located ca. $4 \mathrm{~km}$ away from the influence of the station. After $24 \mathrm{~h}$ acclimatization in aerated clean seawater, they were transplanted for in situ experiments.

Expt 1: An in situ bioassay was carried out in February 1997 to investigate the metal bioaccumulation. Amphipods were placed into cages at 2 sites (Site A located ca. $150 \mathrm{~m}$ from the tip outlet in Brown Bay and Site B located ca. $350 \mathrm{~m}$ from the tip outlet close to Newcombe Bay; Site A inside and Site B outside the plume of dispersion of contaminants; 4 cages per site; 50 ind. per cage) (Fig. 2). The cages, made of 151 white plastic buckets with netting (1 $\mathrm{mm}$ mesh) at the top and bottom, were held vertically at $1 \mathrm{~m}$ depth. The intensity of UV-A and UV-B inside the cages was equivalent at both sites, being reduced to approximately $10 \%$ of the intensity at the water surface during

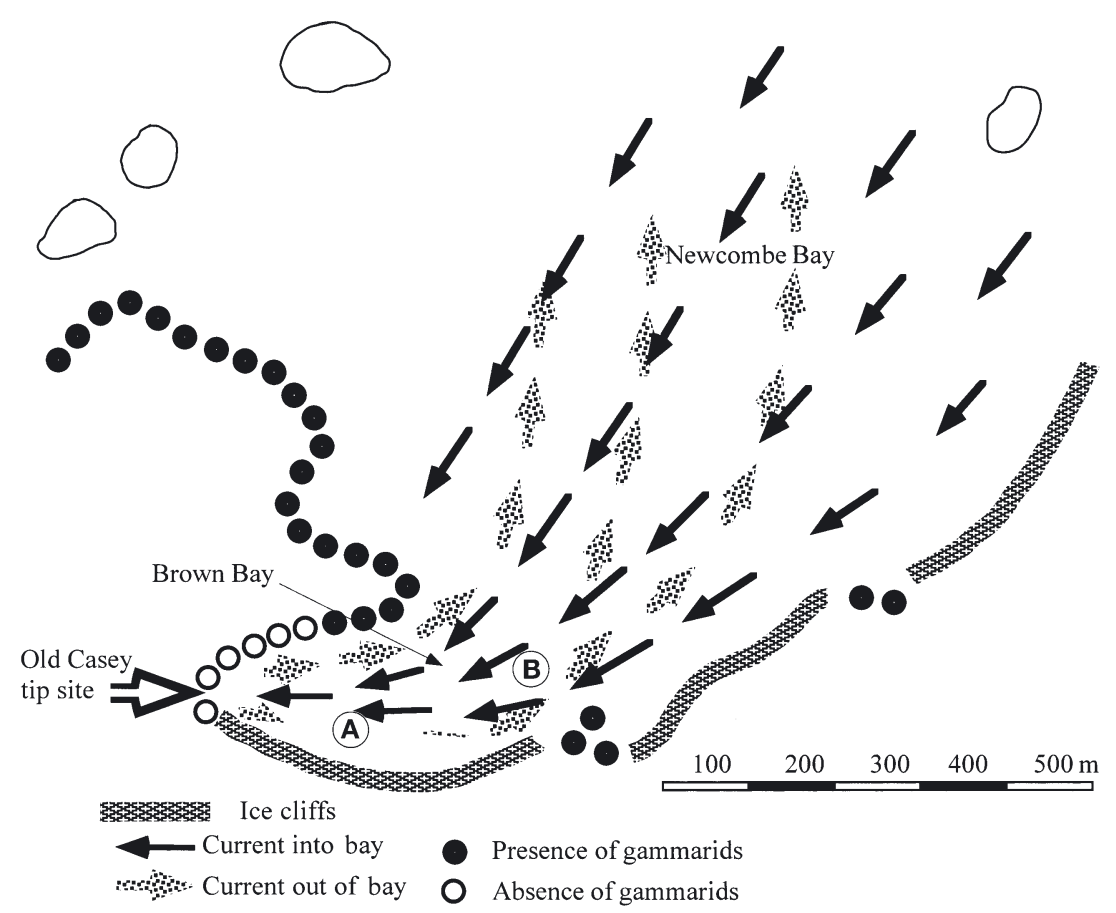

Fig. 2. Dispersion of the plume of tracer from the tip outlet into Brown Bay, transplantation sites (Sites A and B) for the in situ bioassay and natural occurrence of the amphipod Paramorea walkeri along the shoreline 
a cloudless midday (i.e. about $30 \mathrm{~W} \mathrm{~m}^{-2}$ for UV-A and $0.6 \mathrm{~W} \mathrm{~m}^{-2}$ for UV-B). This was quantified with a UV-B radiometer (Dr. Gröbel UV-Elektronik). At the end of the exposure period, the survival was recorded. The remaining individuals from a single bucket were kept in aquaria in clean seawater at $0 \pm 0.5^{\circ} \mathrm{C}$ for $2 \mathrm{~d}$. Then they were pooled, rinsed with distilled water and frozen at $-20^{\circ} \mathrm{C}$ until heavy-metal analysis.

Expt 2: The outdoor test-system experiment was carried out in December 1997 to determine the effects of heavy-metal contamination and solar UV radiation. Flow-through systems made of $50 \mathrm{l}$ plastic aquaria were placed on the sea ice. Two aquaria were located about $150 \mathrm{~m}$ away from the tip outlet in Brown Bay (same as Site A of in situ bioassay) and 2 others were located at a reference site (O'Brien Bay). They received water from $1 \mathrm{~m}$ depth through battery-operated pumps at a flow rate of $10 \mathrm{l} \mathrm{min}^{-1}$. Each system contained 20 plastic vessels of $70 \mathrm{ml}$ capacity, multiperforated to enable a good exchange of the water; the 20 vessels were placed horizontally at the water's surface. A total of 6 amphipods were placed in each vessel. In each aquarium, 10 vessels were covered with a blocking UV filter (txUV, Protex) to protect the amphipods from the solar UV radiation (UV- treatment). The other 10 vessels were covered with a filter that did not reduce the UV significantly (UV+ treatment). Inside the UV+ set up, the intensity of UV-A and UV-B was approximately $30 \%$ of the intensity at the water surface during a cloudless midday, which is equivalent to that at $2 \mathrm{~m}$ depth (i.e. about $10 \mathrm{~W} \mathrm{~m}^{-2}$ for UV-A and $0.2 \mathrm{~W} \mathrm{~m}^{-2}$ for UV-B). In the UV- treatment, UV-A and UV-B were reduced by a factor of about 100 and 20, respectively. Observations to assess survival were made twice daily over the duration of exposure.

The experiments were pursued as long as permitted by weather conditions (18 $\mathrm{d}$ in in situ bioassay and $5 \mathrm{~d}$ for the outdoor test system). The mortality was assessed in both experiments by careful observation of each amphipod (absence of movement of the individual, including absence of respiration [no movement of the gills]). The salinity was monitored at the sites of the bioassays using a salinity meter (WTW, model LF330). Results from the 2 in situ experiments will not be strictly compared as they were performed at different times of the year. Thus, environmental conditions varied to some extent (state of the sea-ice, release of contaminants, UV intensity, wind speed and direction).

Field survey: The natural occurrence of amphipods was monitored qualitatively in 22 locations along the shoreline of the Casey region. The sites investigated (Fig. 1) were selected according to their similarity to Brown Bay (contaminated site) in terms of the physical features that are characteristic of the biotope of
Paramorea walkeri (substrate, depth, exposure to sea ice, wave action etc). At low tide, every $10 \mathrm{~m}$ the shoreline was examined for amphipods in an area of ca. $1 \mathrm{~m}^{2}$, around rocks up to ca. $30 \mathrm{~cm}$ diameter. This survey was performed to link environmental contamination with the occurrence of gammarids as 2 out of the 22 locations were in the vicinity of tip sites (Brown Bay adjacent to the Old Casey tip site and Wilkes adjacent to another tip from Wilkes station that also dates back to the 1960s).

Analyses of heavy metals. Prior to digestion, samples of suspended particulates, sediments and amphipods were dried at $50^{\circ} \mathrm{C}$ under vacuum.

Samples of sediments and amphipods were digested for $18 \mathrm{~h}$ at room temperature in nitric acid (Aristar) in polyethylene-capped tubes $(0.5 / 3 \mathrm{dry} \mathrm{wt} / \mathrm{vol})$, then heated at $90^{\circ} \mathrm{C}$ for $3 \mathrm{~h}$ in a water bath and diluted to constant volumes $(40 \mathrm{ml})$ in distilled water. Blanks and standard reference material (NIST oyster 1566a) were processed using the same procedure.

Filters with suspended particulates were processed similarly, but they were digested in $3 \mathrm{ml}$ of reversed aqua regia; after heating, the extract was evaporated to dryness, to be diluted again in acidified water. Blanks and blank filters were included and considered in calculations of concentrations. In samples from reference sites (i.e. with low heavy-metal content), the concentrations were higher than in blank filters (1.3- to 3-fold depending on the element).

Before heavy-metal analyses, all samples were centrifuged to discard any particulates of the filters; $10 \mathrm{ppb}$ of internal standards were then added. Heavymetal concentrations $(\mathrm{Cd}, \mathrm{Co}, \mathrm{Cr}, \mathrm{Cu}, \mathrm{Ni}, \mathrm{Pb}$ and $\mathrm{Zn})$ were determined by ICP MS (Fissons, PQ2+ STE). The detection limits were equivalent to 3 times the standard deviations of mean values from different blanks.

The seawater samples were prepared according to a method using dithiocarbamate/oxine solvent extraction for the preconcentration of trace metals by metal exchange back-extraction (Batterrham \& Parry 1996). Blank water samples and standard reference materials of seawater (NASS-4 and CASS-3) were also analysed. Metal concentrations were determined by ICP MS. The concentrations in seawater from reference sites were all much higher than the detection limits and concentrations in blanks. The detection limits were 1.6, $0.2,6,2,1.2$ and $12 \mathrm{ng} \mathrm{l}^{-1}$, and the blanks were $<1.6$, $0.5,47,11,20$ and $260 \mathrm{ng} \mathrm{l}^{-1}$ for $\mathrm{Cd}, \mathrm{Co}, \mathrm{Cu}, \mathrm{Ni}, \mathrm{Pb}$ and $\mathrm{Zn}$, respectively.

Analyses of certified reference materials were in the range of 85 to $110 \%$ of the certified values for SRM oyster $1566 \mathrm{a}$, and in the range of 90 to $120 \%$ of the certified values for the water samples (NASS-4 and CASS-3), indicating that digestion and analysis procedures were satisfactory. 
Statistical significance. For the in situ bioassay, the Student $t$-test was used to test for significant differences between the groups of samples (sediment and amphipods) from different locations. For the outdoor test system, ANOVA was used to test for differences between the groups with respect to the effects of solar UV radiation and contaminants. The software Stat View 5 was used for the tests.

\section{RESULTS}

\section{Characterization of the contamination}

\section{Dispersion of contaminants}

The tracer Rhodamin was used as an indicator for the contaminants that had originated from the tip outlet and been dispersed into the adjacent bay (Brown Bay). The results led to the scenario described in Fig. 2: A surface current was bringing fresh seawater into the bay, and the water enriched with tracer from the tip outlet was flowing out of the bay along the shoreline. At ca. $350 \mathrm{~m}$ away from the tip outlet, the contaminated water was flowing underneath the surface stream of incoming seawater; at ca. $1 \mathrm{~km}$, in Newcombe Bay, no stratification could be detected.

\section{Metal concentrations in sediments}

The heavy-metal concentrations in sediments from different locations within the study area showed that the contamination decreased with increasing distance from the tip site: Brown Bay (adjacent to the tip site concerned) > Newcombe Bay (adjacent to Brown Bay) $>$ O'Brien Bay (reference site) (Table 1). All metals tested except $\mathrm{Ni}(\mathrm{Cd}, \mathrm{Cr}, \mathrm{Cu}, \mathrm{Pb}$ and $\mathrm{Zn})$ had significantly higher concentrations in Brown Bay than in
O'Brien Bay ( $t$-test, $\mathrm{p}<0.01$ ), with $\mathrm{Pb}$ and $\mathrm{Cu}$ concentrations about 17- and 3.5-fold higher, respectively.

\section{Heavy-metal concentrations in water and suspended particulates}

The concentrations of some of the heavy metals tested in filtered seawater $(<0.45 \mu \mathrm{m})$ and in suspended particulates tended to be higher in samples of the bay adjacent to the tip site (Brown Bay) than in samples from the reference site (O'Brien Bay; Table 2). In water, the highest concentrations of $\mathrm{Co}, \mathrm{Cu}$ and $\mathrm{Pb}$ were found at the tip outlet, and they decreased as the distance from the tip increased. Zn concentrations were variable, and $\mathrm{Cd}$ and Ni concentrations were relatively similar in samples from all locations. In suspended particulates, mostly $\mathrm{Pb}$ and $\mathrm{Cu}$ (but also $\mathrm{Co}$ and Ni) had higher concentrations in Brown Bay than at 3 different reference sites (Table 2). The concentrations of $\mathrm{Cd}, \mathrm{Cr}$ and $\mathrm{Zn}$ were variable and did not show a pattern linked to the contamination. The heavymetal concentrations in the particulates decreased strongly after the formation of the sea ice, most likely because the meltwater stream had stopped flowing and thus less particulate was released at the tip outlet.

The spatial and temporal changes of concentrations in water and suspended particulates could not be tested for significance due to low numbers of replicates. However, as these changes are substantial, they are not expected to be within the range of variations of replicate measurements.

\section{Assessment of the effects of field exposure on survival of individuals}

The biological effects of environmental conditions, i.e. contamination and solar UV radiation, were assessed by performing in situ experiments and a field survey.

Table 1. Mean concentrations, in $\mu \mathrm{g} g$ dry weight $^{-1}, \mathrm{~N}$ and SD (in parentheses) of heavy metals in (a) composite samples of total sediments from different locations in the Casey station region and (b) Paramorea walkeri (pools of 25 amphipods) after $18 \mathrm{~d}$ exposure at 2 sites (A and B) in Brown Bay. nd: not determined

\begin{tabular}{|lccccccc}
\hline Location & $\mathrm{n}$ & $\mathrm{Cd}$ & $\mathrm{Cr}$ & $\mathrm{Cu}$ & $\mathrm{Ni}$ & $\mathrm{Pb}$ & $\mathrm{Zn}$ \\
\hline (a) & & & & & & & \\
Brown Bay & 3 & $1.11(0.11)$ & $17.90(1.01)$ & $25.29(1.12)$ & $16.64(2.09)$ & $44.66(1.49)$ & $85.31(5.01)$ \\
Newcombe Bay & 3 & nd & $17.12(1.01)$ & $13.5(2.10)$ & $13.98(1.61)$ & $3.03(0.53)$ & $68.88(5.40)$ \\
O'Brien Bay & 3 & $0.74(0.04)$ & $11.57(0.41)$ & $6.87(0.27)$ & $14.05(1.65)$ & $2.61(0.22)$ & $67.95(0.87)$ \\
(b) & & & & & & & \\
Site A (close to tip outlet) & 4 & $4.94(0.30)$ & $1.37(0.18)$ & $26.3(2.06)$ & $5.26(0.21)$ & $3.39(0.89)$ & $68.5(4.69)$ \\
Site B (close to Newcombe Bay) & 2 & $5.11(0.06)$ & $1.20(0.12)$ & $26.3(0.59)$ & $6.02(0.60)$ & $0.90(0.04)$ & $74.5(5.05)$ \\
\hline
\end{tabular}


Table 2. Concentrations (ng $\mathrm{l}^{-1}$ ) of heavy metals in suspended particulates and in filtered seawater $(0.45 \mu \mathrm{m})$ from different locations of the Casey station region. nd: not determined

\begin{tabular}{|c|c|c|c|c|c|c|c|c|c|}
\hline $\begin{array}{l}\text { Site } \\
\quad \text { Sample }\end{array}$ & Location & $\mathrm{n}$ & $\mathrm{Cd}$ & $\mathrm{Co}$ & $\mathrm{Cr}$ & $\mathrm{Cu}$ & $\mathrm{Ni}$ & $\mathrm{Pb}$ & $\mathrm{Zn}$ \\
\hline \multicolumn{10}{|c|}{ Contaminated site (Brown bay) } \\
\hline Particulate & $\begin{array}{l}\text { Tip Outlet } \\
\text { Tip Outlet }{ }^{\mathrm{a}} \\
\text { Outlet }+50 \mathrm{~m} \\
\text { Outlet }+350 \mathrm{~m} \\
\text { Outlet }+350 \mathrm{~m}^{\mathrm{a}}\end{array}$ & $\begin{array}{l}2 \\
2 \\
1 \\
1 \\
1\end{array}$ & $\begin{array}{c}7.0 ; 7.8 \\
2.6 ; 3.6 \\
2.0 \\
6.9 \\
3.4\end{array}$ & $\begin{array}{c}6.9 ; 7.7 \\
1.4 ; 2.7 \\
4.2 \\
4.1 \\
1.3\end{array}$ & $\begin{array}{c}34 ; 74 \\
26 ; 46 \\
\text { nd } \\
73 \\
68\end{array}$ & $\begin{array}{c}1719 ; 6041 \\
80 ; 195 \\
67 \\
65 \\
26\end{array}$ & $\begin{array}{c}41 ; 50 \\
9.8 ; 14 \\
27 \\
26 \\
11\end{array}$ & $\begin{array}{c}1356 ; 1849 \\
93 ; 121 \\
199 \\
74 \\
29\end{array}$ & $\begin{array}{c}2447 ; 11554 \\
312 ; 320 \\
314 \\
291 \\
186\end{array}$ \\
\hline Water & $\begin{array}{l}\text { Tip Outlet } \\
\text { Outlet }+50 \mathrm{~m}\end{array}$ & $\begin{array}{l}1 \\
1\end{array}$ & $\begin{array}{l}83 \\
79\end{array}$ & $\begin{array}{r}18 \\
9\end{array}$ & $\begin{array}{l}\text { nd } \\
\text { nd }\end{array}$ & $\begin{array}{l}913 \\
259\end{array}$ & $\begin{array}{l}418 \\
451\end{array}$ & $\begin{array}{r}148 \\
62\end{array}$ & $\begin{array}{r}3160 \\
586\end{array}$ \\
\hline \multicolumn{10}{|l|}{ Reference site } \\
\hline Particulate & $\begin{array}{l}\text { O'Brien } \\
\text { Clarke } \\
\text { Browning }\end{array}$ & $\begin{array}{l}2 \\
1 \\
1\end{array}$ & $\begin{array}{c}2.8 ; 3.3 \\
4.1 \\
2.3\end{array}$ & $\begin{array}{c}0.6 ; 0.9 \\
1.3 \\
1.0\end{array}$ & $\begin{array}{c}8.8 ; 32 \\
27 \\
36\end{array}$ & $\begin{array}{c}1.2 ; 2.0 \\
38 \\
26\end{array}$ & $\begin{array}{c}4.4 ; 15 \\
10 \\
14\end{array}$ & $\begin{array}{c}16 ; 28 \\
15 \\
9.0\end{array}$ & $\begin{array}{c}136 ; 578 \\
179 \\
101\end{array}$ \\
\hline Water & O'Brien & 2 & $60 ; 76$ & $2 ; 3$ & nd & $132 ; 178$ & $331 ; 369$ & $19 ; 51$ & $919 ; 932$ \\
\hline
\end{tabular}

In the in situ bioassay, the survival of the amphipods Paramorea walkeri, transplanted to 2 sites in the area of the bay contaminated by the releases of the Old Casey tip site (Brown Bay) for $18 \mathrm{~d}$, was significantly lower at Site A close to the tip outlet than at Site B further away, close to Newcombe Bay $(72 \pm 3 \%$ and $99 \pm 1 \%$, respectively) ( $t$-test, p < 0.01). Simultaneously the concentration of $\mathrm{Pb}$ was also significantly higher in the individuals closer to the tip outlet $(t$-test, $\mathrm{p}<0.05)$ (Table 1$)$; it increased by a factor of 4 . Concentrations of $\mathrm{Cd}, \mathrm{Cu}, \mathrm{Ni}$ and $\mathrm{Zn}$ remained comparable in individuals at the 2 sites. Metal concentrations in individuals transplanted close to Newcombe Bay and in individuals from the site of collection (reference site) were comparable (data not presented). Similar experiments conducted in December 1997 confirmed these findings (data not presented).

In the outdoor test system, the influence of solar UV radiation was investigated by exposing individuals to the presence or absence of UV at the site contaminated by releases from the Old Casey tip site (Site A in
Brown Bay) and at a reference site (O'Brien Bay) (Table 3). At the reference site, the survival of amphipods protected from the UV radiation was about $100 \%$ after 5 d exposure, which indicated that the individuals survived the experimental conditions well (Fig. 3). When exposed to the solar UV radiation, the survival decreased significantly after $4.5 \mathrm{~d}$ and reached about $90 \%$ after $5 \mathrm{~d}$. At the contaminated site, the survival of amphipods protected from solar UV radiation was approximately $95 \%$ after $5 \mathrm{~d}$ exposure, whereas it considerably decreased to approximately $78 \%$ under UV exposure. These differences were already significant after 1 and $1.5 \mathrm{~d}$ exposure and also from $3.5 \mathrm{~d}$ until the end of the experiment. Thus, the survival of individuals was lower at the contaminated site than at the reference site; this effect was significant from Day 3.5 when protected and from Day 1 when exposed to solar UV radiation. Two-factor ANOVA showed that there are significant interactions between UV and contamination on Days 1, 1.5, 3.5, 4 and 4.5. On Day 5, this interaction is no longer significant.

Table 3. Significance of ANOVA for the survival of Paramorea walkeri in the outdoor test system as shown in Fig. 3; comparison of results in presence (UV+) or absence (UV-) of solar UV radiation at the reference and contaminated sites. ${ }^{*} \mathrm{p}<0.05$, ${ }^{* *} \mathrm{p}<0.01$, ${ }^{* * *} p<0.001$

\begin{tabular}{|c|c|c|c|c|c|c|c|c|c|c|c|}
\hline \multirow[t]{2}{*}{ Solar UV radiation } & \multirow{2}{*}{ Type of site } & \multicolumn{10}{|c|}{-Time (d) } \\
\hline & & 0.5 & 1 & 1.5 & 2 & 2.5 & 3 & 3.5 & 4 & 4.5 & 5 \\
\hline UV+ and UV- & Reference & & & & & & & & & ** & *** \\
\hline UV+ and UV- & Contaminated & & $*$ & * & & & & $* *$ & *** & $* * *$ & *** \\
\hline UV+ & Reference and contaminated & & $*$ & * & * & $*$ & $* *$ & $* * *$ & $* * *$ & $* * *$ & ** \\
\hline UV- & Reference and contaminated & & & & & & & $*$ & ${ }^{*}$ & $*$ & * \\
\hline $\mathrm{UV} \times$ contamination & & & * & * & & & & $*$ & $* *$ & * & \\
\hline
\end{tabular}


Monitoring of the salinity showed that it remained similar over the duration of the 2 experiments on the different sites $(33.9 \pm 0.2)$.

The field survey was performed at sites that have features characteristic of the amphipod's biotope. It showed that no amphipods were present along the shoreline near the tip site of concern (Brown Bay) and another tip (Wilkes). By contrast they were present at the 20 other sites monitored that are away from contamination sources. This observation strongly supports the idea that the absence of gammarids close to the tip sites is not linked to their natural distribution but rather to the contamination (Figs. $1 \& 2$ ).

\section{DISCUSSION}

This study, which examines the effects of various types of environmental parameters, takes place at a location contaminated by a waste disposal site. Our results showed that the coastal waters were indeed influenced by the heavy metals released from the tip site of concern. The tendencies were as follows:

- Generally higher concentrations in seawater and sediment in samples collected closer to the tip site than further away

- Water generally enriched in $\mathrm{Cu}, \mathrm{Pb}$ and $\mathrm{Co}$ in the bay adjacent to the tip (Brown Bay), compared to reference sites

- Variations of $\mathrm{Cd}$ and $\mathrm{Zn}$ concentrations in water within ranges of concentrations that may reflect the background levels of the area

- Enrichment of heavy metals in sediment, particularly significant for $\mathrm{Pb}$, and secondarily for $\mathrm{Cu}$ (concentrations in Brown Bay were about 17- and 3.5-fold higher for $\mathrm{Pb}$ and $\mathrm{Cu}$, respectively than at the reference site).

The results of an in situ bioassay showed that the amphipod Paramorea walkeri responded to contamination by a significant increase of $\mathrm{Pb}$ concentration in individuals transplanted close to the tip outlet. This indicates that the $\mathrm{Pb}$ present in the environment is at least partly bioavailable. Simultaneously, the survival of the individuals was significantly decreased. The biological effects at the 2 sites of transplantation, varying in distance to the source of contamination, were different and resulted most likely from the difference in heavy-metal contamination. However, it remains uncertain whether contamination is the only factor responsible for the lethal effects observed. Indeed, the low survival of $P$. walkeri recorded at the contaminated site after $18 \mathrm{~d}$ of exposure $(72 \%)$ is most likely not entirely due to the bioaccumulation of $\mathrm{Pb}$ or to the exposure to elevated concentrations of $\mathrm{Pb}$ and $\mathrm{Cu}$ in the environment. These environmental concentrations

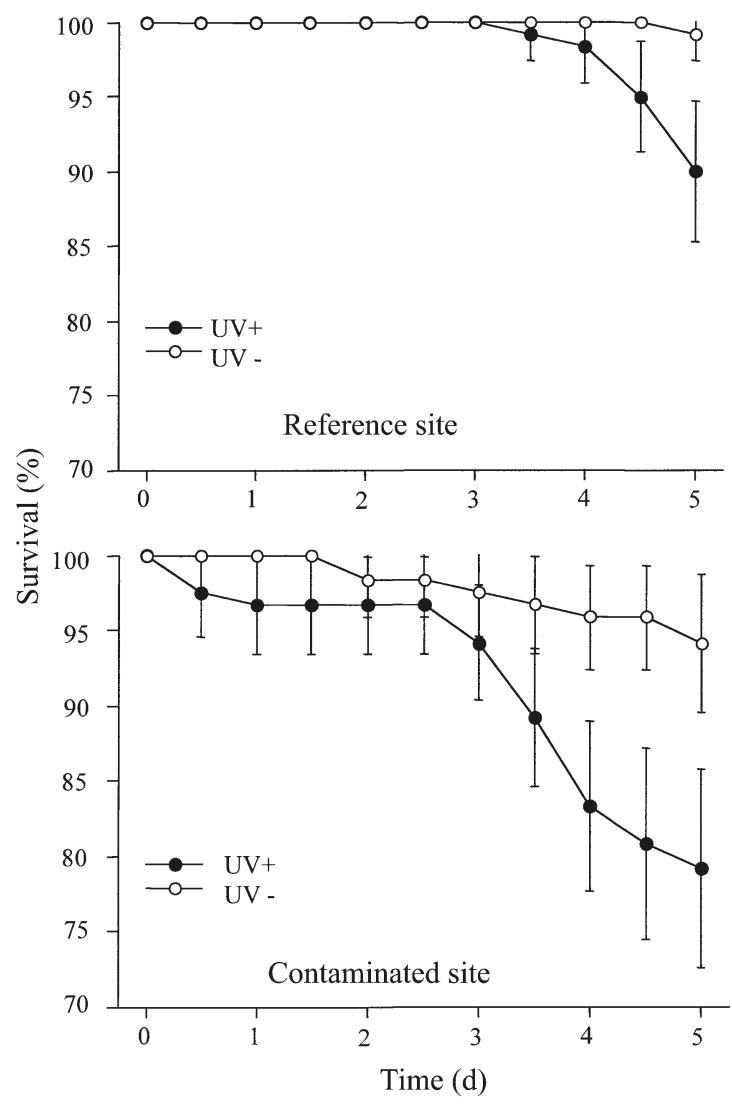

Fig. 3. Paramorea walkeri. Survival of the amphipod transplanted to a reference and contaminated site, when exposed (UV+) or not (UV-) to solar UV radiation (outdoor test system)

(probably below $10 \mathrm{\mu g} \mathrm{l}^{-1}$ ) were several orders of magnitude lower than the toxicity level found in our previous work using the amphipod $P$. walkeri, where we reported $10000 \mu \mathrm{g} \mathrm{Pb} \mathrm{l}^{-1}$ as not highly toxic, and a $4 \mathrm{~d}$ $\mathrm{LC}_{50}$ of $970 \mu \mathrm{g} \mathrm{Cu}^{-1}$ (Duquesne et al. 2000). Furthermore, the contamination measured in the field was not expected to present a risk to the biota, given that the effects range-median from sediment guidelines values (Long et al. 1995) are above the concentrations measured in this location (44.7 and $25.3 \mathrm{ppm}$ for $\mathrm{Pb}$ and $\mathrm{Cu}$, respectively, at the contaminated site vs 2.6 and $6.9 \mathrm{ppm}$ for $\mathrm{Pb}$ and $\mathrm{Cu}$ at the reference site, O'Brien Bay). The disparity between observed and expected effects of contamination indicates a definitely increased sensitivity of the investigated individuals to contamination. Such an effect can be due to reasons such as interactions with environmental parameters other than the contamination itself, which could change the response of various organisms to contaminants, and also have deleterious impacts on the biota.

Of the various potentially contributory environmental parameters, solar UV radiation was selected for further 
investigation because it is relevant to the Antarctic environment. Adverse biological effects of UV-B radiation have been well documented for phytoplankton and zooplankton in both marine and freshwater ecosystems. However, as pointed out by Preston et al. (1999), investigations of interactions between UV-B and anthropogenic contaminants have focused primarily on the chemical interactions between these 2 parameters. Indeed, UV-activation of polycyclic aromatic hydrocarbons (PAHs) and other contaminants has been reported recently (Nikkilä et al. 1999), but UV would not be expected to affect the chemical form of heavy metals in a way that could have major effects on their toxicity. There is no information on combined effects of UV and heavy metals on aquatic animals apart from our recent study performed under laboratory conditions, which revealed an increased sensitivity of Paramorea walkeri to copper (Liess et al. 2001). The relevance of those findings to the field conditions described here was tested in an outdoor test system. The results obtained showed that both field contaminants and solar UV radiation induce deleterious effects on $P$. walkeri. Indeed, individuals exposed to UV have a lower survival than when they are protected from UV. This decrease in survival is much more pronounced at the contaminated site than at the reference site. The effects due to UV also occur earlier in the presence of contaminants; the decrease in survival of individuals exposed to UV compared to those protected from UV was already significant after a relatively short period of exposure $(1 \mathrm{~d})$. This demonstrates the intensity of the biological effects of natural UV radiation, even in the presence of low toxic stress. This significant interaction between the 2 parameters contaminants and UV radiation-indicates that the presence of solar UV radiation increases the sensitivity of $P$. walkeri to contaminants and/or decreases their effective toxic concentration. Such combined action of UV radiation and contaminants has also been shown in organisms such as algae, rotifers and macroinvertebrates under artificial conditions. For instance, UV-B increases the toxicity of pentachlorophenol and mercury to the rotifer Brachionus calyciflorus as much as 5-fold (Preston et al. 1999). Interactive effects of UV-B and copper in the green alga Chlorella vulgaris result in a synergistic inhibition of photosynthetic activity, nutrient (except $\mathrm{NH}_{4}{ }^{+}$) uptake, and enzyme activities (Rai \& Rai 1997). Exposure to UV-B increases the sensitivity of a macroinvertebrate species (the amphipod Paramorea walkeri) to copper, and the resulting lowest-observedeffect concentration was $>30$-fold increased in the presence of UV (Liess et al. 2001). The results of the present study are thus in line with the information provided in the cited laboratory studies. However, in our case study, after a period of time, the interaction between solar UV radiation and contaminants is no longer significant.
This is possibly because above a certain threshold, the contribution of the contaminants to the deleterious effects produced by UV becomes less important.

There remains a question as to the relevance of our findings to the 'real' field situation; in the in situ experiments, individuals had no opportunity to hide or escape from the solar UV radiation or from the contamination. It was thus interesting to investigate the response of the amphipod population naturally occurring along the shoreline. Among all sites considered as appropriate biotopes, it was only in the vicinity of tip sites (Old Casey and Wilkes) that amphipods were absent. According to the results of in situ experiments, this is likely to be a result of decreased survival at those locations. In addition, avoidance behaviour might be responsible for the observed absence of the gammarids. For instance, the closely related freshwater species Gammarus pulex is known to respond with such behaviour when exposed to various classes of insecticides (Liess 1993). Such avoidance behaviour would imply that the absence of the gammarid Paramorea walkeri along the shoreline was linked to the environmental stress. Thus, the effects observed during in situ experiments on the individuals would be reflected at a population level.

\section{CONCLUSION}

This case study showed that environmental parameters such as solar UV radiation exert biological effects that are increasing the detrimental effects of contaminants. This information adds to the knowledge required for an optimised management and protection of specific ecosystems, such as the Antarctic environment. In a more general aspect, this work leads to the suggestion that the combined action of various stressors should be included in higher-tier risk assessment in order to improve the interpretation of potential risks and reduce uncertainties.

Acknowledgements. We thank the Australian Antarctic Division and particularly Dr Martin Riddle, leader of the Human Impact Program. We gratefully acknowledge the valuable inputs of Dr R. Schulz of the Technical University of Braunschweig, and the help of Dr B. Emison of the Museum of Melbourne and Dr A. Greig of the University of Queensland. We are also grateful to M. Greve, C. King and the staff of Casey station. This research was supported by a grant from the Australian Antarctic Science Advisory Committee.

\section{LITERATURE CITED}

Batterham GJ, Parry DL (1996) Improved dithiocarbamate/ oxine solvent extraction method for the preconcentration of trace metals from seawater using metal exchange backextraction. Mar Chem 55:381-388 
Bothwell ML, Sherbot DMJ, Pollock CM (1994) Ecosystem response to solar ultraviolet-B radiation: influence of trophic level interactions. Science 265:97

Crane M, Maltby L (1991) The lethal and sublethal responses of Gammarus pulex to stress: sensitivity and sources of variation in an in situ bioassay. Environ Toxicol Chem 10: 1331-1339

Cripps G (1990) Hydrocarbons in the seawater and pelagic organisms of the Southern Ocean. Polar Biol 10: 393-402

De Moreno JEA, Gerpe MS, Moreno VJ, Vodopivez C (1997) Heavy metals in Antarctic organisms. Polar Biol 17: 131-140

Deprez PP, Arens M, Locher H (1999) Identification and assessment of contaminated sites at Casey station, Wilkes land, Antarctica. Polar Rec 195:299-316

Duquesne S, Riddle M, Schulz R, Liess M (2000) Effects of contaminants in the Antarctic environment-potential of the gammarid amphipod crustacean Paramorea walkeri as a biological indicator for Antarctic ecosystems based on toxicity and bioacccumulation of copper and cadmium. Aquat Toxicol 49:131-143

Lenihan HS (1993) Benthic marine pollution around McMurdo Station, Antarctica: a summary of findings. Mar Pollut Bull 25:318-323

Liess M (1993) Zur Ökotoxikologie der Einträge von landwirtschaftlich genutzten Flächen in Fließgewässer. Cuvillier, Göttingen

Liess M, Schuz R (1999) Linking insecticide contamination and population response in an agricultural stream. Environ Toxicol Chem 18:1948-1955

Liess M, Champeau O, Riddle M, Schulz R, Duquesne S (2001) Combined effects of ultraviolet-B radiation and food shortage on the sensitivity of the Antarctic amphipod

Editorial responsibility: Otto Kinne (Editor),

Oldendorf/Luhe, Germany
Paramoera walkeri to copper. Environ Toxicol Chem 20(9): 2088-2092

Long ER, McDonald DD, Smith SL, Calder FD (1995) Incidence of adverse biological effects within ranges of chemical concentrations in marine and estuarine sediments. Env Manage 19(1):81-97

Moore PG, Rainbow PS, Hayes E (1991) The beach-hopper Orchestia gammarellus (Crustacea: Amphipoda) as a biomonitor for copper and zinc: North Sea trials. Sci Total Environ 106:221-238

Nikkilä A, Penttinen S, Kukkonen JVK (1991) UV-B-induced acute toxicity of pyrene to the waterflea Daphnia magna in natural freshwaters. Ecotoxicol Environ Safety 44: $271-279$

Preston BL, Snell TW, Kneisel R (1991) UV-B exposure increases acute toxicity of pentachlorophenol and mercury to the rotifer Brachionus calyciflorus. Environ Pollut 106(1):23-31

Rai PK, Rai LC (1997) Interactive effects of UV-B and Cu on photosynthesis, uptake and metabolism of nutrients in a green alga Chlorella vulgaris under simulated ozone column. J Gen Appl Microbiol 43(5):281-288

Rainbow P (1995) Biomonitoring of heavy metal availability in marine environment. Mar Pollut Bull 31:183-192

Snape I, Stark JS, Cole CM, Gore DG, Duquesne S, Riddle MJ (2001) Management and remediation of contaminated sites at Casey Station, Antarctica. Polar Rec 37(202):199-214

Worrest RC, Hader DP (1989) Effects of stratospheric ozone depletion on marine organisms. Environ Conserv 16(3): 261-263

Zauke GP, Meurs HG, Butte W (1995) Validation of estuarine gammarid collectives (Amphipoda: crustacea) as biomonitors for cadmium in semi-controlled toxicokinetic flowthrough experiments. Environ Pollut 90:209-219

Submitted: September 2, 2002; Accepted: January 31, 2003 Proofs received from author(s): June 4, 2003 